\title{
LA PSICOTERAPIA INTEGRATIVA EN EL ÁMBITO DE INTERVENCIÓN SOCIAL: CONCEPTOS Y MÉTODOS DE INTERVENCIÓN
}

\author{
INTEGRATIVE PSYCHOTHERAPY IN SOCIAL \\ INTERVENTION DOMAIN: \\ CONCEPTS AND METHODS OF INTERVENTION
}

\author{
Angela Pérez Burgos \\ Doctora en psicología. Alcalá de Guadaíra, Sevilla, España \\ ORCID: https://orcid.org/0000-0003-1596-9853
}

\begin{abstract}
Cómo referenciar este artículo/How to reference this article:
Pérez Burgos, A. (2021). La Psicoterapia Integrativa en el ámbito de intervención social: conceptos y métodos de intervención. Revista de Psicoterapia, 32(118), 149-162. https://doi.org/10.33898/rdp. v32i118.490
\end{abstract}

\begin{abstract}
Resumen
La Psicoterapia Integrativa ofrece unas herramientas exquisitas para implementar el contacto de calidad en las relaciones profesionales establecidas dentro del ámbito social. Los profesionales que se dedican a la relación de ayuda llevan a cabo intervenciones que resultan eminentemente reparadoras -sin hacer psicoterapia propiamente dicha-por lo que puede suponerles un enriquecimiento aplicar los principios, conceptos y métodos de la Psicoterapia Integrativa en las interacciones con sus diferentes usuarios. La relación reparadora que entablan se considera el medio para desarrollar el trabajo especifico con cada persona usuaria y el escenario para potenciar el crecimiento y nuevas conductas. En este artículo se describirá la Psicoterapia Integrativa en ámbitos de intervención social desde 3 pilares básicos: la persona profesional, la persona usuaria y la relación reparadora

Palabras clave: indagación, sintonía, implicación, relación de ayuda
\end{abstract}

\begin{abstract}
Integrative Psychotherapy offers unique tools to implement quality contact in professional relationships established also within the social domain. The professionals who are dedicated to the helping relationship carry out interventions that are highly reparative so it can be an enrichment to apply the principles, concepts and methods of Integrative Psychotherapy in the interactions with their different users. The reparative relationship they establish is considered the means to develop the specific work with each user and the setting to promote growth and new behaviors. Integrative Psychotherapy in social field it will be described from 3 basic pillars: the professional, her/his user and the reparative relationship.
\end{abstract}

Keywords: inquiry, attunement, involvement, helping relationship

Fecha de recepción: 27 de septiembre de 2020. Fecha de aceptación: 6 de noviembre de 2020

Correspondencia sobre este artículo:

E-mail: angelaburgos@gmail.com

Dirección postal: Calle Mairena 42, 4 .41500 Alcalá de Guadaíra, Sevilla, España

(C) 2021 Revista de Psicoterapia

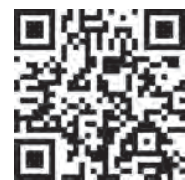


Existen numerosos modelos teóricos que describen enfoques diferentes para la intervención social (psicológicos, filosóficos, pedagógicos, familiares-sistémicos, técnicos, comunitarios, socio-laborales...). Fernández (2017) detalla estos diferentes modelos y postula que según el modelo humanista "el ser humano, complejo y complicado, es el protagonista central de un proceso que debe conocer sus anhelos y sus miedos, sus valores y sus experiencias, y que debe apoyar el crecimiento personal por encima de patologías psicológicas” (p.18).

Siguiendo esta línea, la Psicoterapia Relacional Integrativa (creada por Richard G. Erskine), una de las escuelas psicoterapéuticas humanistas más recientes, refleja además en su premisa central que el contacto constituye la experiencia motivadora primaria de la conducta humana. Su marco teórico ofrece unas herramientas extraordinarias para establecer el contacto de calidad en las relaciones profesionales con diferentes usuarios (niños, adolescentes, familias, víctimas de violencia de género, personas mayores, personas con discapacidad, personas con adicciones, etc.) dentro también del ámbito social. El grupo de profesionales a los que se refiere este artículo incluye psicólogos, educadores sociales, trabajadores sociales y trabajadores familiares, entre otros.

La esencia que aportan los conceptos de contacto interno (consciencia propia) y contacto externo (consciencia de la otra persona) y así como el de relación (entendida en este caso como el medio para la reparación, para incrementar el nivel de autoconocimiento, el espacio seguro donde practicar nuevas conductas y poner en acción patrones relacionales más saludables) van a definir cada interacción:

"La relación se construye sobre el contacto interpersonal. Pero el verdadero contacto interpersonal es posible solamente si uno está en contacto consigo mismo" (Erskine et al., 1999/2012, p.226).

Los aspectos relacionales incluyen características tales como:

1. La calidad de la interacción profesional-persona usuaria

2. El establecimiento del contacto pleno

3. El acompasamiento del ritmo de la intervención

4. La resonancia afectiva

5. La atención a las necesidades relacionales

El profesional de ayuda trabaja desde una posición de igualdad, respeto y normalización, basada en los principios filosóficos de la Psicoterapia Integrativa (Erskine, 2015/2016), está centrado en el crecimiento más que en el cambio, y asume la responsabilidad de su intervención, incluidos los errores que pudiera cometer (Guistolise, 1996).

Uno de los mayores retos en el ámbito social es el tiempo disponible para invertir en los "casos"; y sí, el contacto y la relación requieren tiempo para consolidarse. De ahí la relevancia de la calidad del contacto que pueda establecer el profesional con la mayor agilidad posible. Cuanto mejor sea su nivel de contacto interno adquirido (consciencia sobre su cognición, fisiología y afectos), con mejor calidad interpersonal invitará a la persona usuaria a establecer la relación reparadora, 
así como a mejorar su nivel de autoconocimiento. En áreas como la drogadicción y la violencia de género, pueden presentarse carencias en la consciencia personal de la gravedad de la situación, lo que conlleva a veces a minimizar la necesidad de ayuda e incluso la urgencia de esa ayuda.

Elementos básicos de contacto interno: ser consciente de las sensaciones y emociones que despierta la persona con la que se interactúa, los pensamientos que se generan en la intervención con ella, las reacciones fisiológicas que emergen (pautas de respiración, ritmo cardíaco, sudoración, etc.).

Elementos básicos de contacto externo: qué se percibe en la otra persona en cuanto a reacciones emocionales, respuestas cognitivas, lenguaje no verbal, contacto visual, fluidez del encuentro, etc.

En la experiencia de trabajo con adolescentes, no resulta extraño encontrarse a veces con la dificultad de poder conectar con el mensaje real emitido porque la respuesta emocional manifestada tiene un efecto amplificado en el proceso de comunicación.

Una joven adolescente a la que se le pregunta en un tono neutral por qué ha ocultado el resultado de sus notas sabiendo que existe esa información del centro escolar, puede tener una reacción de enfado desproporcionada que esconde una profunda sensación de vergüenza. Si el profesional sólo reacciona ante el enfado y desatiende los efectos de la vergüenza, las transacciones con esta joven resultarán muy pobres, con lo que la posibilidad de crecimiento en esta experiencia queda mermada.

Contacto, conexión y relación van a reflejar las dinámicas relacionales. Crecemos y maduramos en relación. A través de ella, aprendemos sobre nosotros. La relación con pleno contacto, donde se establece un nivel de conexión óptimo, es la que posibilitará la satisfacción de las necesidades relacionales (Erskine et al., 1999/2012). Si bien en este artículo no se van a describir las 8 necesidades relacionales dentro del enfoque de Psicoterapia Integrativa, cabe resaltar algunas de ellas para ejemplificar su aplicación en la práctica del ámbito social.

Si tomamos en consideración la necesidad de seguridad, es decir, de sentirse protegido por otra persona, ésta podría considerarse como una base de inicio a la hora de entablar la relación de ayuda. La persona usuaria que experimenta la sensación de seguridad, que puede asumir que no será avergonzada o criticada por parte del profesional, podrá mostrar su intimidad y vulnerabilidad en presencia de éste. En el área de trabajo con personas mayores, resulta de vital relevancia reflejar esta seguridad en el trato cotidiano con personas dependientes, estén en domicilio o en centros residenciales. Esta seguridad se demuestra en pequeños grandes detalles como la hora de la higiene (delicadeza en el tacto), asistencia para la alimentación y el vestido (paciencia y adaptación al ritmo personal), actividades lúdicas (iniciativa y creatividad para romper la rutina y el asilamiento), etc.

Otra base de inicio importante es la necesidad de validación, es decir, ser significativo en la relación; se satisface cuando la persona usuaria acepta que no 
solo es “un caso más”, sino que se siente vista y tratada como única. Este mensaje de "eres importante para mí" emitido por el profesional (a nivel tanto verbal como conductual, con palabras y con hechos) marca la diferencia de la intervención. Muchos profesionales han vivido en directo reacciones como "tú estás aquí porque necesitas el dinero", "me tienes que aguantar porque para eso te pagan”, "te vas a tu casa y te olvidas de todos” ... reacciones fruto de la propia ausencia acumulativa de satisfacción de necesidades relacionales en la historia de la persona usuaria. Estas reacciones aparentes de rechazo, no deben desanimar al profesional comprometido con su labor de continuar en la relación de calidad. Pueden aprovecharse para explorar los acontecimientos vitales de la historia de esa persona e incluso para explorar la relación ya establecida con el profesional (miedos, inseguridades, desconfianzas...) que puede reflejarse en los patrones relacionales aprendidos sobre los que se puede trabajar.

Cada persona usuaria con la que se entabla la relación de ayuda requiere un ritmo único y a veces, aún con la mejor intención, el profesional puede aportar más de lo que esa persona puedes digerir en un momento dado. El equilibrio sutil supone un constante reajuste del nivel de atención, dedicación y profundidad que evite la sensación de yuxtaposición (Erskine et al., 1999/2012). La relación de ayuda representa un reto frente a todo lo vivido en el pasado. Este contraste entre el contacto disponible con el profesional y la carencia de contacto en las anteriores relaciones resulta a menudo más de lo que las personas usuarias pueden soportar, por tanto, se protegen del contacto presente para evitar así recuerdos emocionales o carencias actuales en relaciones significativas. Las emociones y las conductas expresadas, suponen un intento de negar y no reconocer las memorias emocionales o no querer asumir la percepción de la carencia. A menudo la yuxtaposición se manifiesta rechazando al profesional después de un encuentro cercano.

En casos de abusos físicos o sexuales, las reacciones de yuxtaposición pueden indicar que la intensidad de la implicación resulta demasiado intensa y no permite la existencia de una sensación de seguridad.

En el trabajo con infantes y adolescentes de centros de acogida, centros residenciales educativos o inmersos en procesos de adopción, las reacciones de yuxtaposición expresan que el profesional está estableciendo un contacto de calidad relacional pero, en ese momento, resulta difícil de manejar porque podría estar activando pensamientos asociados a creencias como "mejor no me fio de nadie y menos de éste...", "parece buena persona pero seguro que me falla...", "yo no necesito ayuda de nadie...”, por lo que el profesional debe replantearse el ajuste de la frecuencia y la intensidad de ese contacto ya que esa novedosa relación saludable está activando también la consciencia de la carencia de relación adecuada con personas significativas previas (progenitores que han abusado, criticado, maltratado, abandonado...).

La historia vital de carencias en la satisfacción de necesidades relacionales constituye un aspecto común generalizado de las personas usuarias que solicitan los 
diferentes servicios de atención. Las heridas relacionales del pasado se recrean en la actual relación de ayuda. De hecho, incluso pueden observarse comportamientos que corresponden a edades más tempranas. Si bien el nivel de intervención social no persigue una terapia profunda, mantener el concepto de imagen evolutiva, imaginar en la mente a qué edad corresponderían las expresiones emocionales y conductuales observadas (Erskine, 2019) puede orientar las pautas de intervención.

Por ejemplo, en una adolescente funcional y competente residente de un piso asistido, cercana a su mayoría de edad (con todo lo que conlleva el miedo a enfrentarse a su propia independencia y autonomía al tener que "abandonar" la seguridad de un recurso residencial que ha sido su hogar en los últimos años), resulta frecuente observar conductas regresivas como acting-outs, aislamiento, dificultades para cumplir la normativa, bajo rendimiento académico, ausencias injustificadas, conductas desafiantes hacia los educadores del centro, conflictos con los demás residentes, etc.

Ante situaciones de esta índole, replantearse un acompañamiento que equilibre las interacciones adultas con interacciones que incluyan atención a aspectos más infantiles (evitando la presión de las exigencias adultas constantes) puede ayudar a esta joven a recuperar la calma y la confianza o, al menos, a sentirse más protegida, acompañada y segura. En esta etapa, la necesidad relacional de depender de alguien en quien poder confiar y apoyarse resulta crucial.

En Psicoterapia Integrativa estaríamos hablando en este caso de sintonía evolutiva -cuando el profesional puede percibir y adaptarse a la edad evolutiva de la persona con la que realiza la intervención- y sintonía con las necesidades relacionales - cuando el profesional identifica qué necesidades no se han cubierto, qué necesidades están aflorando en la relación y cómo satisfacerlas.

La sintonía, junto con la implicación y la indagación, conforman los métodos relacionales de la Psicoterapia Integrativa (Erskine et al., 1999/2012). Estos métodos, uno de los sellos de identidad de este modelo y una de sus aportaciones más significativa, están diseñados para implementar la relación reparadora. Representan una combinación de arte y ciencia, de aspectos humanos y aspectos técnicos; reflejan la actitud y la aptitud del profesional en su labor de acompañamiento para promover el bienestar.

Los tres métodos, indagación, sintonía e implicación se interrelacionan entre sí y están conceptualizados como el eje central desde donde se origina la intervención terapéutica. En el ámbito social, su aplicación aporta una comprensión general sobre el proceso de establecer la relación reparadora y desde ella, contribuir al crecimiento de la persona usuaria y a la transformación de algunos aspectos que están interfiriendo en su realización como persona de área tan diversas como la relacional, laboral, social, familiar, personal, lúdica, salud, etc.

Los métodos aportan la guía para la implementación de la relación profesionalpersona usuaria con el foco puesto en el establecimiento del contacto pleno y de la calidad relacional con el fin de crear un clima de bienestar donde primen la confianza 
y la seguridad, garantizar el espacio donde poder compartir y explorar, e incrementar así la consciencia y el autoconocimiento de la persona usaría. Experiencias de desatención y maltrato (en sus diferentes manifestaciones) en la historia vital han originado serias dificultades para que se atreva a abrirse, expresar emociones, compartir inquietudes o mostrarse, si no percibe un grado suficiente de acogida, dedicación y presencia por parte del profesional que le atiende.

La calidad de la relación mutua se ve mejorada por la dinámica que el profesional establece a través de la indagación ("Me gustaría conocerte y comprender más sobre ti mientras te vas descubriendo"), sintonía ("Respeto tu propio ritmo y te acompaño a tu propio paso”) e implicación (“ Eres importante y me preocupo por ti, te lo demostraré").

Aunque son conceptos creados originalmente dentro del contexto terapéutico (Erskine et al., 1999/2012), la práctica profesional demuestra buenos resultados en el campo de la psicología social. A continuación se definen de una forma breve y descriptiva los métodos relacionales.

\section{Métodos Relacionales}

\section{Indagación}

Supone una demostración de interés genuino y curiosidad auténtica por parte del profesional hacia lo que le sucede a la otra persona. Se brinda la experiencia de ir más allá del mero hecho de ser preguntado, se inicia desde "Quiero saber más de ti” (tu pasado, proyectos, experiencias, sueños, miedos, anhelos, etc.) asumiendo que el conocimiento más relevante de este proceso es el que adquirirá la propia persona usuaria sobre sí misma. Resulta crucial comunicar y transmitir con mucho respeto para alentar a compartir a nivel personal y minimizar reacciones de crítica interna, vergüenza, retraimiento... Desde la indagación, se incluye y se hace posible también la exploración de la relación co-creada. Esto conlleva analizar aspectos que hayan podido originar fricciones y malestar entre ambos participantes involucrados en el proceso.

\section{Sintonía}

Enseña a tener en cuenta el ritmo, no invadir con demandas o exigencias, esperar el momento adecuado, no malinterpretar el distanciamiento, no hacer intervenciones apresuradas. Cuando la otra persona está lista, hay cercanía y apertura emocional. Refleja una actitud de "estoy aquí contigo y te respeto". Mantiene el ajuste a cada etapa de desarrollo evolutivo como una prioridad. En otras palabras, la consciencia de los requisitos específicos de cada ciclo vital (infancia, adolescencia, edad adulta, senescencia), incluyendo las necesidades relacionales. La sintonía afectiva facilita, desde la resonancia del profesional, una reacción acorde con la expresión emocional de la persona usuaria, y, de este modo, se toma en serio su enfado (hacia él u otras personas), protege del miedo, comparte la alegría y acoge la tristeza con 
compasión. Proporciona un contacto interpersonal más allá de las palabras.

\section{Implicación}

Pone el énfasis en el mensaje "eres importante para mí”. Las habilidades del profesional están al servicio de la atención y el bienestar de la persona a la que trata. A su vez, el profesional, presente en la relación, se siente afectado en sus propias reacciones, respuestas y emociones. Es importante recalcar que el profesional trabaja desde una vertiente humana, no solo técnica. La implicación incluye estar completamente presente cuando el profesional realiza la intervención con la persona usuaria, como una forma de transmitir seguridad. El profesional, en ese momento, está centrado en su atención y lo pone de manifiesto; y con ello refleja que es digno de confianza.

Se detallarán a continuación las características básicas del enfoque de Psicoterapia Integrativa desde 3 pilares fundamentales.

\section{Profesional}

\section{Asume que no Conoce la Experiencia Interna del Cliente}

Explora con curiosidad e interés genuino: aunque el trato con la persona usuaria facilita un mayor conocimiento sobre ella, resulta esencial mantenerse abierto a nuevas reacciones y a nuevas respuestas que surgen a lo largo de la intervención y que van aportando diferente información en la fascinante tarea de descubrir los aspectos más significativos de la persona usuaria.

\section{Crea un Espacio de Seguridad}

Este espacio incluye los aspectos físicos del entorno (privacidad acústica, orden e higiene, estructura de la sala...), pero sobre todo incide en las actitudes del profesional que garantizan la ausencia de críticas, de respuestas humillantes o de comentarios vergonzantes hacia la persona usuaria.

\section{Establece un Ambiente de Confianza}

Hace hincapié en los aspectos relacionales que generan una acogida emocional (respeto, ritmo no invasivo, presencia, aceptación) para que la persona usuaria consiga abrirse y mostrarse de forma auténtica.

\section{Domina Herramientas de Intervención (Métodos)}

El profesional de la relación de ayuda posee un nivel de formación que incluye los métodos de indagación, sintonía e implicación. Conoce el modo de gestionarlos y los aplica adecuadamente en las transacciones que establece, manteniendo como prioridad la relación reparadora. 


\section{Se Responsabiliza de Errores Terapéuticos}

Cometer errores es inevitable. El profesional los reconoce y asume en la relación. Al responsabilizarse de ellos, ofrece una experiencia, a veces única, a la persona usuaria. Con frecuencia, resulta una situación novedosa para la persona usuaria que el profesional comparta con ella que se ha equivocado (desde un error de agenda, hasta uno asociado a la intervención -malentendido, falta de empatía, indicación equivocada, precipitación, asunción incorrecta) y ofrezca una oportunidad de enmendar la situación.

\section{Dispone de un Alto Nivel de Contacto (Interno y Externo)}

Supone una calidad de consciencia de sus aspectos personales y de la consciencia del contacto con la persona usuaria. Conoce qué dinámicas internas propias influyen en su relación mientras establece las dinámicas interpersonales con la personal usuaria.

\section{Es Considerada como Figura Adulta "Más Fuerte y Más Sabia"}

La potencia que le otorgan tanto su experiencia como sus conocimientos, y la protección que emana de su capacidad de generar seguridad y confianza la convierten en esa persona "más fuerte y más sabia".

\section{Conoce sus Fortalezas y Debilidades}

Sus propios puntos fuertes y, además, aquellos aspectos que necesita mejorar, con el fin de que no interfieran en su labor profesional. Asume un aprendizaje personal y profesional constante.

\section{Prioriza la Relación como Elemento Esencial del Proceso Reparador}

Conoce los beneficios de las herramientas relacionales (contacto, intimidad, confianza, vulnerabilidad) desde donde analiza cada intervención. Se concentra en la calidad relacional como beneficiosa para el proceso de ayuda.

\section{Adopta un Posicionamiento de Igualdad hacia la Persona Usuaria}

Evita considerarse "superior" o de mayor valía ante la persona con la que interviene. Trabaja desde un posicionamiento de “yo estoy bien, tú estás bien” más allá de la dificultad vital y el sufrimiento expresados en la relación.

\section{Elabora Diagnósticos Basados en Perturbaciones Relacionales, No Patologías}

Si bien en el ámbito social no se emplea el diagnóstico clínico como tal, el profesional de enfoque integrativo, sabe interpretar éste desde la dificultad en el establecimiento de relaciones saludables que ha sufrido la persona usuaria en etapas previas y a lo largo de su vida. 


\section{Trabaja con Imágenes evolutivas}

Detecta mentalmente las edades previas de la persona usuaria; tiene en cuenta manifestaciones (conductuales, cognitivas y emocionales) de la etapa evolutiva que corresponde a cada persona usuaria en el momento la intervención y que se asemejan en su modo de hablar, la posición del cuerpo, gestos faciales y reacciones emocionales a una persona de edad más joven. En momentos concretos, la persona usuaria responde como lo hacía en su infancia o adolescencia.

\section{Enfocado en el Crecimiento, No en el Cambio}

Acompañar en el proceso de crecimiento a una persona, origina procesos de cambio naturales, marcados por el ritmo de dicha persona, no por el profesional. En el ámbito social, la presión de la limitación de recursos asistenciales (carencia de medios) actúa en detrimento de este proceso natural de cambio.

\section{Manifiesta Sentimientos y Emociones}

Desde la consciencia personal mencionada con anterioridad, el profesional se muestra a nivel emocional sin esconder sus reacciones, siempre manteniendo como prioridad el bienestar de la persona usuaria. Esta manifestación emocional es acorde y proporcionada a cada particularidad de la intervención.

\section{Comparte Experiencias Propias}

Si el profesional considera adecuado en beneficio de la persona usuaria exponer una situación personal relacionada con lo que está compartiendo en un momento determinado esa persona usuaria, hablará de dicha experiencia.

\section{Alienta a Examinar la Relación Profesional Establecida}

La relación en sí misma forma parte del contenido compartido en cada intervención. El profesional inicia la exploración de aspectos asociados a su relación con el interés puesto en mantener la calidad relacional en un nivel saludable y eliminar elementos que supongan una interferencia en esta calidad.

\section{Persona Usuaria}

\section{Establece un Proceso Intersubjetivo Único con el Profesional}

Cada persona es singular, y como tal, el proceso que se crea entre ella y el profesional mantiene unas características exclusivas. No existen "recetas" colectivas, cada intervención está ajustada y adaptada a la persona que en ese momento necesita de la intervención. 
Presenta Dificultades Relacionales Normalmente Originadas en Etapas Tempranas

La experiencia vital de cada historia personal ha marcado los patrones relacionales que se van a poner en acción en la actualidad y con el profesional. De ahí la importancia de conocer aspectos evolutivos básicos y situar la intervención según la experiencia relacional previa. La desconfianza hacia el profesional nace del maltrato, los abusos y la negligencia sufrida anteriormente por la personal usuaria.

\section{Necesita Intervenciones en Todos sus Ámbitos (Afectivo, Cognitivo, Conduc- tual y Fisiológico)}

Aun presentando más dificultad o problemática en un área determinada, la intervención se beneficiará del enfoque completo hacia la persona, incluyendo también el ámbito espiritual.

\section{Manifiesta Conductas (Consideradas a Veces como "Raras" o "Inmaduras") que Tuvieron Sentido en un Momento Dado}

Las experiencias previas han conformado una forma de actuar, a veces no consciente, que tuvo sentido en un momento dado. Lo importante sería cuestionar, en el instante oportuno, si ese sentido se mantiene en la situación actual.

\section{Muestra Formas de Actuar, Pensar y Sentir que Corresponderían a Etapas Evolutivas Previas}

Se ha señalado previamente la relevancia de prestar atención a estos aspectos evolutivos que aportan una información relevante y orientan la actuación profesional. No considerarlos podría suponer una experiencia que originaría a veces un enquistamiento del problema.

\section{Pone en Acción Patrones Relacionales Aprendidos con Figuras Significativas de su Infancia}

Valorar esos patrones originados del modelaje aportado por personas significativas supondrá el primer paso para trabajar la idoneidad de estos en el momento presente y las consecuencias en la vida actual de la persona usuaria.

\section{Expresa Carencias en la Satisfacción de las Necesidades Relacionales}

De ahí la relevancia de poder contar con el profesional como la persona con la que aprenderá a hacerlas conscientes y a satisfacerlas: una de las tareas clave es determinar el nivel de satisfacción de necesidades relacionales que presenta la persona usuaria, conocer cómo se cubrieron o no estas necesidades. Ayudarle a darse cuenta, explorarlas juntos, compartir sobre esa experiencia ayudará a replantearse nuevos patrones. El profesional se convierte temporalmente en la fuente de satisfacción de necesidades relacionales. 
Refleja Dificultades de Contacto Interno y Contacto Externo, No Conscientes

Suele ser habitual que la persona usuaria se relacione, de forma no consciente, desde una fachada social. No ha aprendido a mostrarse, sobre todo porque ha carecido de oportunidades para practicar su autenticidad. Hay aspectos de sí que desconoce, lo que complica conectar con los demás. El profesional le invitará a explorarse y a conocerse para facilitar y poner en práctica nuevas dinámicas.

\section{Mantiene su Propio Ritmo en la Comunicación, desde su Estilo Cognitivo y} Afectivo

Por eso necesita la resonancia del profesional: el profesional tiene que adaptarse y no imponer su propio ritmo, ya que claramente se perjudicaría el proceso y se pondría en peligro el nivel de contacto que se está estableciendo.

\section{Anhela la Relación, Aunque la Teme, por Experiencias Fallidas Previas}

Como ser humano, desea mantenerse en contacto, pero si lo que ha vivido en el pasado le ha enseñado que es mejor permanecer distante con las personas y desconfiar, presentará lógicamente dificultades iniciales en la relación con el profesional.

\section{Relación Reparadora}

\section{Relación Co-creada entre Profesional y Persona Usuaria}

Será una relación basada en un contacto pleno generado por el profesional: este contacto ofrecido por el profesional es el que genera la invitación a la personal usuaria. El profesional se convierte en el elemento facilitador para la relación reparadora que ambos establecen juntos.

\section{Elemento Esencial para que se Produzca la Reparación}

En ausencia de relación, la intervención corre el riesgo de mecanizarse, hacerse automática. Esto impacta de forma negativa en la persona usuaria, reforzando el desaliento y el desánimo para lidiar con sus dificultades.

\section{Área Segura donde la Persona Usuaria Pone en Práctica Nuevos Patrones Relacionales (Conductas, Fantasías, Reacciones Fisiológicas, etc.) \\ A través de la relación reparadora se crea un nuevo escenario para ensayar conductas que se está aprendiendo y que, suponiendo aún un reto, demuestran el beneficio, primero dentro de la relación con el profesional y después en la relación con las demás personas.}

\section{Ámbito de Actuación que Facilita la Consciencia de Aspectos No Conocidos a la Persona Usuaria}

La persona usuaria tiene la posibilidad de conocerse mejor y con mayor profundidad cuando se encuentra ante un profesional que la acoge, que la acepta, que 
comprende su malestar y que le acompaña en el proceso de hacerse más consciente.

Entorno dónde se Prioriza el Bienestar y el Crecimiento de la Persona Usuaria

La relación reparadora está al servicio de cada persona que requiere la ayuda, la persona usuaria prima en la intervención. El profesional trabaja en objetivos asumidos conjuntamente que potencian los beneficios que obtiene dicha persona usuaria.

\section{Aspecto más Relevante en el Proceso Reparador que el Contenido en el que se Trabaja}

Sin menospreciar ningún tema de los que se trabajan en la intervención de ayuda, ni la relevancia de aspectos que determinan el problema presentado, desde el enfoque de la Psicoterapia Integrativa, se hace patente la esencia de mantener como elemento central la relación. Sin el trabajo relacional, la reparación no puede ocurrir.

ESPACIO donde:

1. no solo se pregunta, se indaga: la exploración se realiza a través de cuestiones, afirmaciones, reflexiones, énfasis verbales... todos ellos enfocados a conocer a la persona usuaria, pero sobre todo a que sea ella la que se vaya conociendo cada vez más y mejor.

2. no se critica ni se juzga, se acepta: esto evita la autocrítica tan común y tan frecuente entre las personas que necesitan de intervención. La experiencia de ser aceptada alienta la apertura emocional y disminuye el miedo a mostrarse vulnerable ante el profesional.

3. la exploración está al servicio de la persona usuaria: quien se convierte en la protagonista del proceso. El profesional guía y orienta desde su experiencia y nivel de competencia, pero siempre es la persona usuaria quien decide qué rumbo tomar.

4. la persona usuaria se siente única: sabe que su intervención está diseñada desde el respeto a su singularidad. Siente y percibe un trato exclusivo por parte del profesional al que ha acudido.

A modo de síntesis, se presenta en la siguiente tabla un esquema que resume los 3 pilares (tabla 1): 
Tabla 1. Los tres pilares

PROFESIONAL

Asume que no conoce la experiencia interna del cliente (explora con curiosidad e interés genuino)

Crea un espacio de seguridad

Establece un ambiente de confianza

Domina herramientas de intervención (métodos)

Se responsabiliza de errores terapéuticos

Dispone de un alto nivel de contacto (interno y externo) Es considerada como figura adulta "más fuerte y más sabia" Conoce sus fortalezas y debilidades

Prioriza la relación como elemento esencial del proceso reparador Adopta un posicionamiento de igualdad hacia la persona usuaria Elabora diagnósticos basados en perturbaciones relacionales, no patologías Trabaja con imágenes evolutivas (edades previas de la persona usuaria), tiene en cuenta la etapa evolutiva que corresponde a cada usuario en el momento la intervención. Enfocado en el crecimiento, no en el cambio

Manifiesta sentimientos y emociones Comparte experiencias propias Alienta a examinar la relación profesional establecida
PERSONA USUARIA

Establece un proceso

intersubjetivo único

con el profesional

Presenta dificultades relacionales

normalmente originadas

en etapas tempranas

Necesita intervenciones en todos

sus ámbitos: afectivo, cognitivo,

conductual y fisiológico

Manifiesta conductas

(consideradas a veces

como "raras" o "inmaduras")

que tuvieron sentido en

un momento dado

Muestra formas de actuar, pensar

y sentir que corresponderían

a etapas evolutivas previas

Pone en acción patrones

relacionales aprendidos con

figuras significativas de su infancia

Expresa carencias en la

satisfacción de las necesidades

relacionales, de ahí la

relevancia de poder contar con

el profesional como la persona

con la que aprenderá a hacerlas

conscientes y a satisfacerlas

Refleja dificultades de

contacto interno y contacto

externo, no conscientes

Mantiene su propio ritmo en

la comunicación, desde su

estilo cognitivo y afectivo (por

eso necesita la resonancia

del profesional)

Anhela la relación, aunque

la teme, por experiencias

fallidas previas

\section{RELACIÓN REPARADORA}

Relación co-creada entre profesional y persona usuaria, basada en un contacto pleno generado por el profesional Elemento esencial para que se produzca la reparación Área segura donde la persona usuaria pone en práctica nuevos patrones relacionales (conductas, fantasías, reacciones fisiológicas, etc.) Ámbito de actuación que facilita la consciencia a la persona usuaria de aspectos no conocidos Entorno dónde se prioriza el bienestar y el crecimiento de la persona usuaria

Aspecto más relevante en el proceso reparador que el contenido en el que se trabaja ESPACIO donde:

1. no solo se pregunta, se indaga

2. no se critica ni se juzga, se acepta

3. la exploración está al servicio de la persona usuaria

4. Ia persona usuaria se siente única

\section{Conclusiones}

El modelo de intervención social desde la Psicoterapia Integrativa se puede implementar en cualquier servicio (pisos asistidos, hogares de acogida, residencias de mayores, centros de tratamiento, recursos educativos, etc.) donde la interacción personal forme parte de la tarea profesional diaria. El foco principal de atención está dirigido a la interacción, al "quién y cómo" es la persona con quien el profesional se relaciona, cuáles son sus necesidades, cómo reaccionan, qué expresan, etc. 
La conducta externa disruptiva que puede aparecer, se considera la manifestación de un conflicto interno que debe comprenderse, porque ese conflicto interno puede explicar dicha conducta y darle sentido. "No hay personas sin contexto" (Sánchez et al, 2018).

La intimidad en la relación profesional-persona usuaria genera una proximidad emocional entendida como el acto de aceptar y compartir sentimientos y poner a disposición la capacidad empática que facilitará la expresión de la variedad de emociones sin temor al rechazo o la crítica.

Este enfoque permite aceptar al profesional cómo le afecta la otra persona y descarta la posición de "Soy mejor que tú", "Sé más que tú”... con lo que en a su vez evita la necesidad de que la persona atendida se tenga que proteger psicológicamente. Comporta un trato exquisito en la relación establecida por el profesional y un reconocimiento serio y profundo hacia la persona que requiere su ayuda.

\section{Referencias}

Erskine, R. G. (2016). Presencia terapéutica, patrones relacionales: conceptos y práctica de la Psicoterapia Integrativa. (A. Pérez Burgos, Trad.). Karnac. (Trabajo original publicado en 2015)

Erskine, R. G. (2019). Developmentally based, relationally focused Integrative psychotherapy: Eight essential points [Psicoterapia integrativa basada en el desarrollo y centrada en las relaciones: Ocho puntos esenciales]. International Journal of Integrative Psychotherapy, 10, 1-10. http:/www.integrative-journal.com/ index.php/ijip/article/view/144

Erskine, R. G., Moursund, J. P. y Trautmann, R. L. (2012). Más allá de la empatía: una Terapia de Contacto-enla-Relación. (N. Mestre, Trad.). Desclee de Brouwer. (Trabajo original publicado en 1999)

Guistolise, P. (1996). Failures in the therapeutic relationship: Inevitable and necessary? [Fallos en la relación terauéutica: ¿Inevitable y necesario?]. Transactional Analysis Journal, 26(4), 284-288. https://doi. org/10.1177/036215379602600403

Fernández, S. (2017). La teoría en la Intervención social. Modelos y enfoques para el trabajo social del siglo XXI. Acción social. Revista de política social y servicios sociales, 1(1), 9-43. http://hdl.handle.net/10201/51521

Sánchez, A. M., Martínez, M. F., Piñero, R., Torres, J. A., Pérez, L. A., Eguzquiza, I., Ollero, A., Rovira, J. y Rodríguez, M. A. (2018). Reflexiones en torno a la Psicología de la Intervención Social y el Sistema de Servicios Sociales. Consejo General de la Psicología de España. https://doi.org/10.23923/cop.PISoc.2018 